\title{
Research on the Discrimination of Hatching Eggs Activity Based on Thermal Imaging: A Food Nondestructive Testing Practice
}

\author{
Liu Hai-ling, Cai Jian-rong*, Sun Li, Yuan Lei-ming and Liu Meng-lei \\ School of Food and Biological Engineering, Jiangsu University Zhenjiang 212013, \\ China \\ * Corresponding author: Cai Jian-rong (liu1989910@126.com)
}

\begin{abstract}
The hatching eggs in 4-16 days incubation were from incubator of $38.5^{\circ} \mathrm{C}$ to $22^{\circ} \mathrm{C}$ for natural cooling and the time series images were acquired by thermal imaging technology. Analyzing the cooling curve and the cooling area and region growing, ellipse fitting, morphological processing and other methods were used to extract eggs region of interest; time series images superposition and contrast enhancement were used to raise the temperature close to the different categories of eggs gray differences; the ratio of gray value $\leqq 150$ and entire ROI area was seen as characteristic parameters and the decision threshold was set according to minimum error rate Bayes rule. The non-fertilized eggs in incubating 4 days was $89.6 \%$ overall recognition and the dead embryo eggs in incubating 16 days was $96.3 \%$ overall recognition. Research showed that thermal imaging technology combined image processing technology can achieve non-destructive testing of hatching eggs activity.
\end{abstract}

Keywords: Hatching eggs; Thermal imaging; Activity; Image processing

\section{Introduction}

Hatching eggs activity is an important indicator of its quality and the current hatching success rate is $80 \%-96 \%$ [1]. The main reason is the part of unfertilized eggs and dead embryo in the hatching eggs, that wasting a lot of labor and energy, as there is the risk of bacterial infection other eggs. In actual production, hatching eggs quality conditions are detected by manual eggs candling in 5-7 days incubation, at this unfertilized eggs have lose food value and manual eggs candling is time-consuming, labor-intensive and easy to subjective factors. So quick, non-destructive testing in the incubation process can improve the level of automation egg hatching industry and has some practical value.

During hatching egg incubation, embryo in the yolk developed gradually and formed a large number of blood vessels, due to evaporation, absorption, metabolism and other factors, yolk and protein nutrients was consumed, making internal changes in the composition. Based on this process, the fertilized eggs' current detection are mainly according to differences in the optical, vibration and spectral characteristics, machine vision [2,3], near-infrared spectroscopy [4], percussion vibration [5] and hyper-spectral images [6] are adopted to detect hatching egg quality. But the research is still in the laboratory stage, these studies are affected by eggshell color, thickness and other factors, and most of the use of complex processing and classification algorithms to overcome the effects of individual differences or environmental interference, unable to meet the intelligent testing requirements online .

In recent years, thermal imaging technology in non-destructive testing of agricultural products develops rapidly, have been widely used in fruits and vegetables quality control $[7,8]$, grain quality and safety assessment $[9,10,11]$, foreign matter detection $[12,13]$ and so on. In the use of thermal imaging technology for hatching egg quality detection, Danno used thermal imaging to determine the fertilized eggs and unfertilized eggs, the results 
show that the incubation period, the fertilized eggs than unfertilized eggs surface temperature $0.3-1.3{ }^{\circ} \mathrm{C}$ [14]; Lin utilized egg hatching two weeks thermal imaging, using Sobel operator to extract eggs outline, computing GLCM eigenvalues to distinguish eggs activity, the overall recognition rate of $90 \%$ [15]. Currently the study is still at the laboratory stage, test specimens were single batch of hatching eggs, the adjacent eggs heat radiation phenomenon wasn't considered.

This paper uses thermal imaging technology to obtain hatching eggs image sequence at low excitation conditions. According to hatching eggs cooling process characteristics image enhancement methods were used to improve hatching eggs distinguishability of different activities, and extracting an area with a relatively high temperature than the overall area of the eggs as the characteristic parameter to determine the activity. Experimental results show that this method has high recognition rate.

\section{Test Equipment, Materials and Methods}

\subsection{Test Equipment}

Hatching eggs thermal imaging detector is shown in Figure 1, including computers, thermal imagers (FLIR A615, thermal sensitivity of $0.05^{\circ} \mathrm{C}$ ), sealed boxes and egg trays. Among them, the thermal imager is connected to a computer, using BM_IR software to obtain hatching eggs surface temperature information; sealed box is used for suppressing interference generated by uneven air flow around and temperature was controlled at $22 \pm$ $2{ }^{\circ} \mathrm{C}$; egg tray is used for placing test hatching eggs smoothly and keeping in a stationary state.

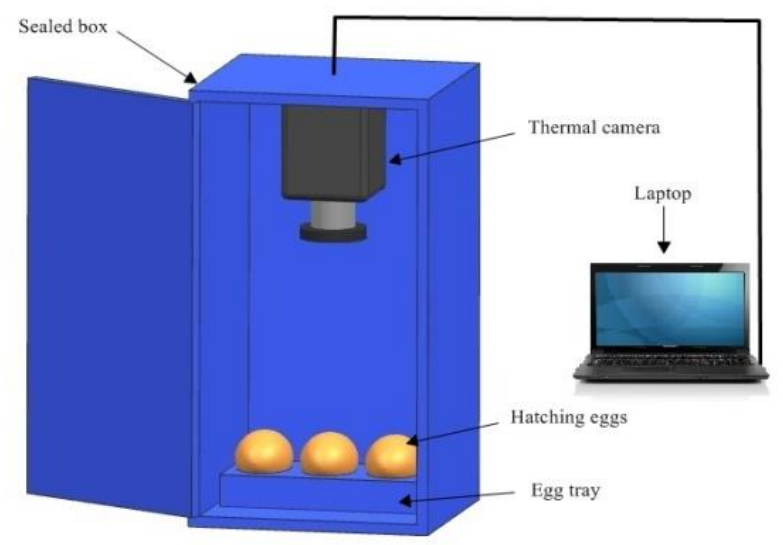

\section{Figure 1. Schematic Diagram of Thermal Imaging Detection Device}

\subsection{Test Materials and Methods}

Test samples are from Zhenjiang Wintrobe Animal Husbandry Limited Company, 4 to 16 days incubation, the number of 288 , temperature inside incubator and relative humidity were $38.5 \pm 1{ }^{\circ} \mathrm{C}$ and $57.0 \pm 5 \%$. Hatching eggs are divided into six batches for testing, in order to eliminate the time difference from the incubator to detection means, collecting hatching eggs thermal images after removal from the incubator two minutes, the sampling interval $15 \mathrm{~s}$, continuous acquisition $15 \mathrm{~min}$ recording eggs cooling process. After all the chicks hatching, destructive testing for not out of chicken hatching eggs, observing for the 
non-fertilized or dead embryo eggs, it conducts a standard compared to the detecting results of thermal technology.

\section{Eggs Image Generation and Cooling Characteristics}

\subsection{Image Generation}

In order to visualize the temperature information, the ranges of $20-40{ }^{\circ} \mathrm{C}$ temperature field is converted to 8-bit gray-scale images by equation(1), gray-scale temperature field shown in Figure 2, a block diagram marked as non-fertilized eggs, the rest is fertilized egg, the image resolution of $640 \times 480$.

$$
\mathrm{g}(\mathrm{x}, \mathrm{y})=\operatorname{round}\left(\frac{255 \times(f(x, y)-20)}{20}\right)
$$

Equation(1), $(x, y)$ for image pixel coordinates, $\mathrm{f}(x, y)$ for corresponding point $(x, y)$ temperature value, $\mathrm{g}(x, y)$ for the corresponding coordinates $(x, y)$ of image gray value, round for the rounding operation.

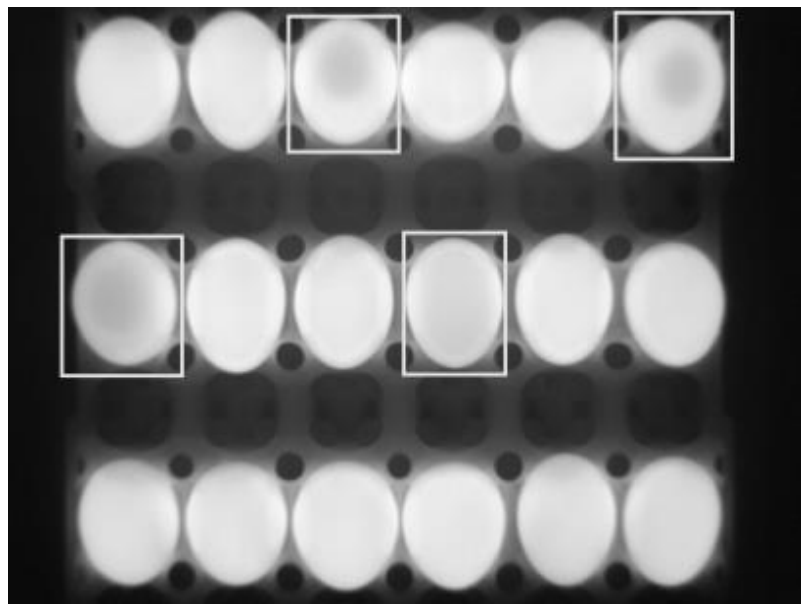

Figure 2. Hatching Eggs Grayscale

\subsection{Cooling Curve and the Cooling Area}

Due to differences in temperature and humidity at different locations inside the incubator, choosing the same batch of eggs for the study object, eggs average surface temperature characterizes the egg surface temperature. As shown in figure 3 , in the natural cooling process, the living embryo eggs temperature is always higher than nonfertilized eggs, but the temperature difference is slightly different. As for the dead embryo eggs, temperature is close to live embryo in 4 days of incubation, between live embryo eggs' and dead embryo eggs' in 8 and 12 days of incubation, close to dead embryo eggs' in 16 days of incubation. The reason may be that dead embryo eggs have active in the early incubation, lose activity due to some reason in the hatching process. 


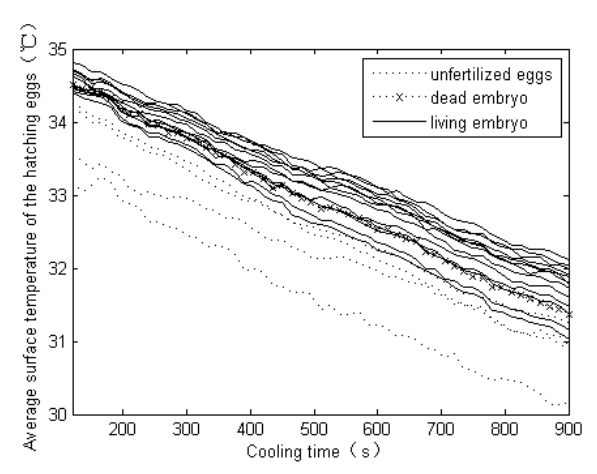

(a)4 days incubation

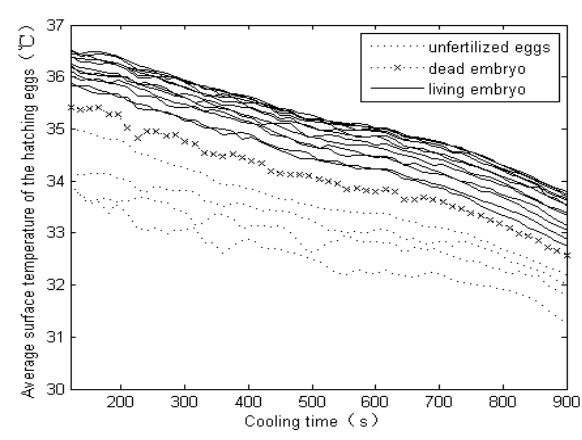

(c)12 days incubation

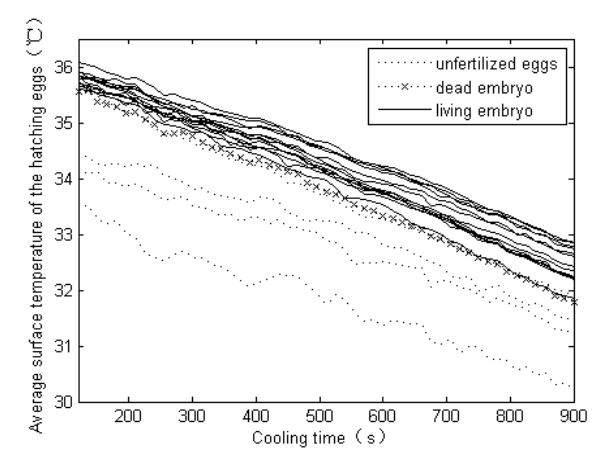

(b)8 days incubation

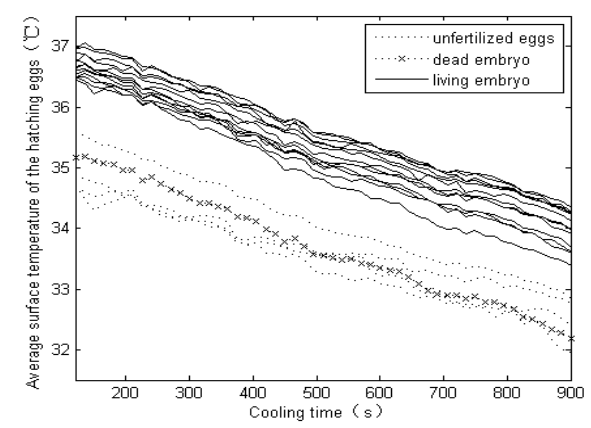

(d)16 days incubation

Figure 3. Average Surface Temperature Change Curve of a Batch of Hatching Eggs in Different Incubation Days and Natural Cooling Process

In thermodynamics, as long as the test system temperature $\mathrm{T}$ is higher than the surroundings temperature $\theta$, the system will cool to the outside world and lower the temperatures. According to Newton's law of cooling, when the difference between the system temperature $\mathrm{T}$ and surroundings temperature $\theta$ does not exceed $50{ }^{\circ} \mathrm{C}$, the system cooling rate is proportional to $(T-\theta)$, namely

$$
\frac{\mathrm{d} Q}{d t}=K_{0}(T-\theta)
$$

Equation (2), ${ }^{\mathrm{k}_{0}}$ is the heat transfer coefficient, that is determined on the surface state of the object (such as the shape, surface area, etc.); $\mathrm{Q}$ is the heat; when $(T-\theta)$ is not big, $\mathrm{k}_{0}$ is a constant. Equation (2) is converted to

$$
\mathrm{d} Q=k_{0}(T-\theta) d t
$$

By integral operation of equation (3), it can be obtained system surface heat dissipation $\Delta Q$ between $\mathrm{t}_{0}$ with $\mathrm{t}$ :

$$
\Delta Q=k_{o} \int_{t_{0}}^{t}(T-\theta) d t
$$




$$
\frac{\Delta Q}{\mathrm{k}_{0}}=\int_{t_{0}}^{e}(T-\theta) d t
$$

In conjunction with Figure $3.7, \frac{\Delta Q}{k_{0}}$ can be seen as $x=t_{0}, x=t$, surroundings temperature curve (assuming the surroundings temperature constant in the same batch of hatching eggs natural cooling process) and hatching eggs cooling fitting line enclosed the area. The paper is represented by cooling area.

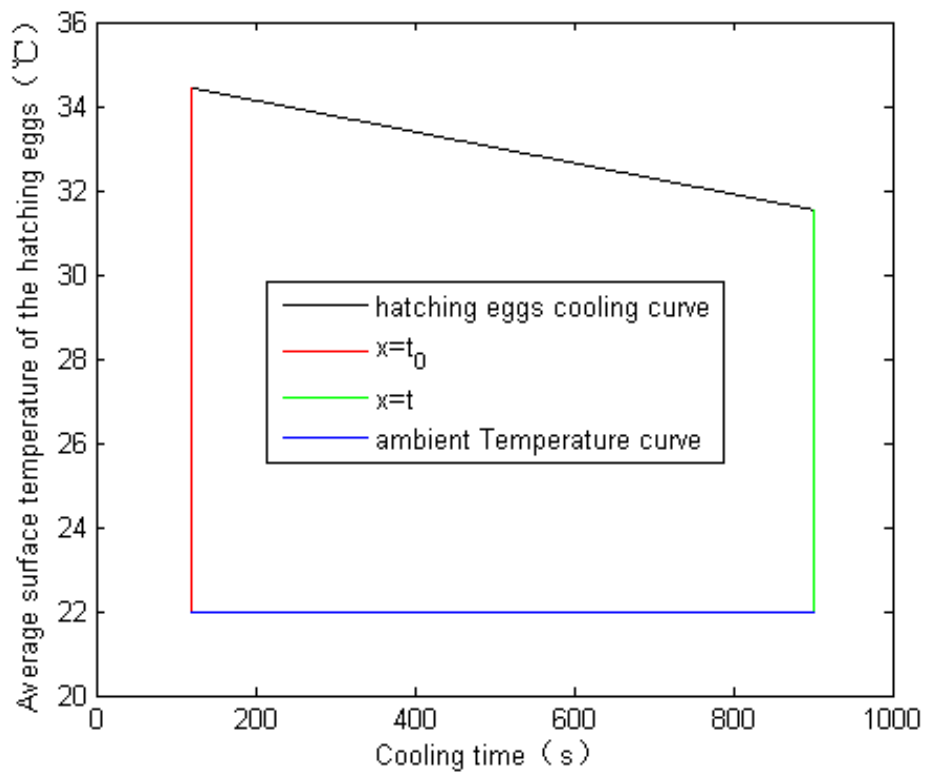

Figure 4. Hatching Eggs Cooling Area

As shown in Table 1, initial temperature of No.14 living embryo eggs and No.15 nonfertilized eggs was $34.36^{\circ} \mathrm{C}$ and $34.20^{\circ} \mathrm{C}$, live embryo eggs temperature is $0.47 \%$ higher than the non-fertilized eggs. While cooling area of No.14 living embryo eggs and No.15 non-fertilized eggs was $8321.48\left({ }^{\circ} \mathrm{C} \cdot \mathrm{s}\right)$ and $8194.99\left({ }^{\circ} \mathrm{C} \cdot \mathrm{s}\right)$, live embryo eggs cooling area is $1.52 \%$ higher than non-fertilized eggs. Therefore, it can increase temperature close to different categories of hatching eggs difference by calculating hatching eggs cooling area.

Table 1. Initial Temperature and Cooling Area of 4 Days Incubation's Hatching Eggs in Natural Cooling Process

\begin{tabular}{|c|c|c|c|}
\hline $\begin{array}{c}\text { Serial } \\
\text { number }\end{array}$ & Eggs category & $\begin{array}{c}\text { Eggs initial temperature }\left({ }^{\circ} \mathrm{C}\right. \\
)\end{array}$ & $\begin{array}{c}\text { Cooling area }\left({ }^{\circ} \mathrm{C} \cdot \mathrm{s}\right. \\
)\end{array}$ \\
\hline 1 & living embryo & 34.81 & 8876.06 \\
\hline 2 & living embryo & 34.72 & 8807.29 \\
\hline 3 & living embryo & 34.69 & 8765.08 \\
\hline 4 & living embryo & 34.66 & 8871.91 \\
\hline 5 & living embryo & 34.58 & 8806.50 \\
\hline 6 & living embryo & 34.57 & 8727.07 \\
\hline 7 & dead embryo & 34.50 & 8508.25 \\
\hline
\end{tabular}




\begin{tabular}{|c|c|c|c|}
\hline 8 & living embryo & 34.49 & 8511.98 \\
\hline 9 & living embryo & 34.48 & 8641.89 \\
\hline 10 & living embryo & 34.45 & 8688.41 \\
\hline 11 & living embryo & 34.45 & 8523.61 \\
\hline 12 & living embryo & 34.43 & 8379.75 \\
\hline 13 & living embryo & 34.41 & 8321.48 \\
\hline 14 & living embryo & 34.36 & 8194.99 \\
\hline 15 & $\begin{array}{c}\text { unfertilized } \\
\text { eggs }\end{array}$ & 34.20 & 7960.18 \\
\hline 16 & $\begin{array}{c}\text { unfertilized } \\
\text { eggs }\end{array}$ & 34.03 & 7492.44 \\
\hline 17 & $\begin{array}{c}\text { unfertilized } \\
\text { eggs }\end{array}$ & 33.48 & 73.19 \\
\hline
\end{tabular}

\section{Hatching Eggs Images Processing and Activity Recognition}

\subsection{Image Processing Eggs}

Heat transfer characteristics differences in hatching eggs, egg tray and background great, hatching eggs surface gray value changed small with the background of distinguishability obviously. So the method of regional growth is used to segment the target of various hatching eggs, specifically: Each pixel in the image were seen as seeds and 4 neighborhood point of this seeds gray value difference $\leqq 4$ was divided into the same area, large than 4000 pixels area was reserved, extracted hatching eggs area was shown in Figure 5a. Hatching eggs edges is not irregular and target region extraction is not complete by this method extracting. To assume hatching egg as an ellipsoid, ellipse fitting was used to repair the defect area (Figure 5b). Hatching eggs edge was vulnerable to other hatching eggs heat radiation and can't accurately characterize the actual temperature. Therefore, radius of 15.5 pixels circular structure was used to hatching eggs fit area erosion operation and the reserved area is a region of interest (ROI) for subsequent processing (Figure 5c).

The ROI gray value of each batch image sequence was superimposed processing and structured into 8-bit images (Figure 5d). The superimposed image gray value focused on 150-255 and histogram equalization processing was used to tensile contrast, the results as shown in Figure 5e. Different activities of hatching eggs have higher distinguishability, but there were individual non-fertilized eggs (as in the second line of the fourth) and fertilized eggs (as in the third line of the sixth) gray value difference not significant, this could be due to the placement of the eggs caused environmental interference. Each hatching eggs were enhanced in local high frequency region to amplify implied highfrequency information, the results shown in Figure 5f.

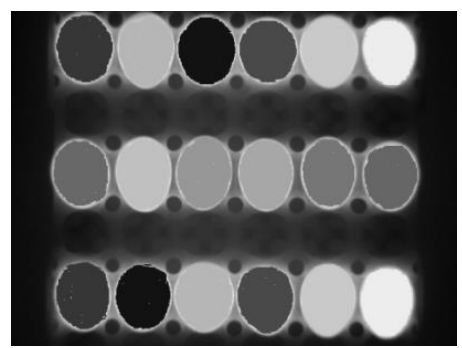

(a) Region growing segmentation
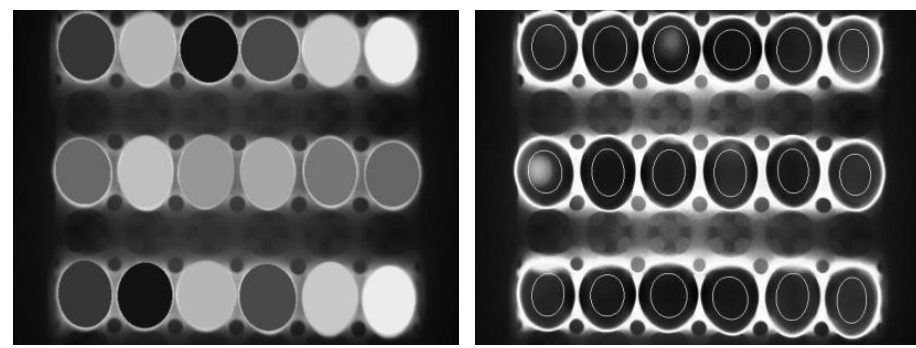

(b) Ellipse fitting (c) Hatching eggs pseudo-color figure and ROI 


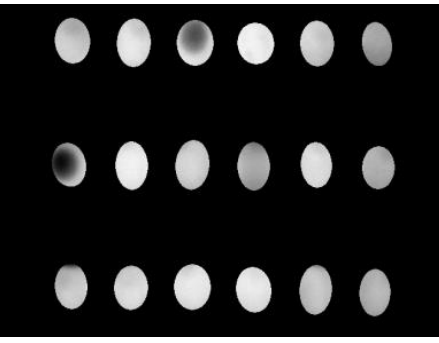

(d) Image superposition figure

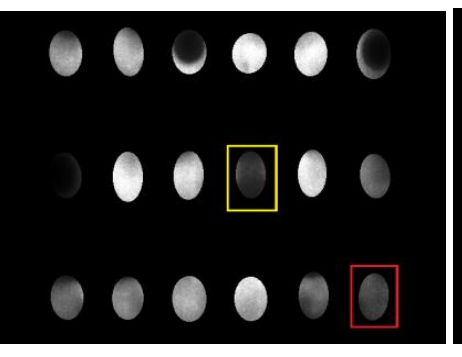

(e) Histogram equalization figure

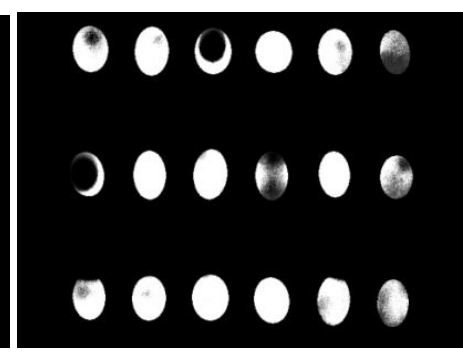

(f) Contrast enhancement

Figure 5. Processing Results of Hatching Eggs Thermal Image

\subsection{Eggs Activity Discrimination}

After image enhancement, the ROI of fertilized eggs and unfertilized eggs gray histogram was shown in Figure 6. It was shown that the area of gray value $\leqq 150$ fertilized eggs greater than unfertilized eggs. Taking into account the different size hatching eggs, the ratio of gray value $\leqq 150$ and the whole ROI area was discrimination features of hatching eggs activity.

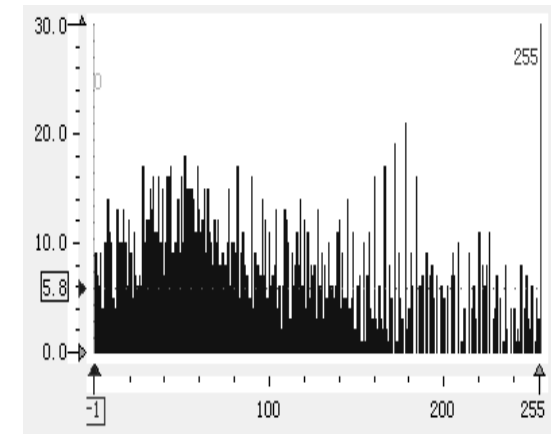

(a) Unfertilized Eggs Histogram

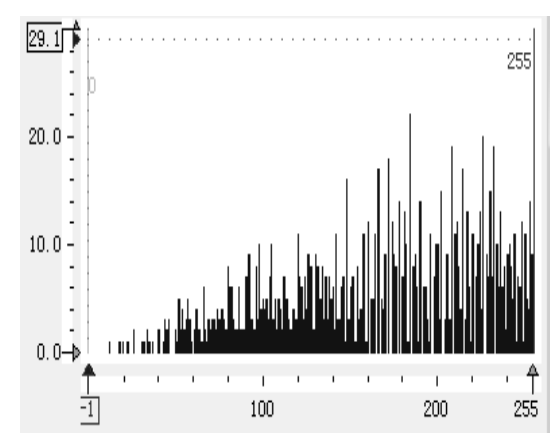

(b) Fertilized Eggs Histogram

Figure 6. Hatching Eggs Histogram

\subsubsection{Identification of Unfertilized Eggs}

Unfertilized eggs would lose value after long time incubation, the area ratio in incubating 4 day was seen characteristic parameter. Area ratio minimum error rate Bayes rule was used to distinguish different active hatching eggs and investigating the effect of the test results in the time-series images superimposed number, results shown in Figure 6. It could be found that detection accuracy would improve with the increasing number of image superposition. The accuracy reached maximum with the superposition number 12 and time-series images superposition had no value. Therefore, the test parameters were determined as follows: 12 thermal images after leaving incubator 2-5min were superimposed and the activity of hatching eggs could be determined. 288 hatching eggs were divided into calibration set and prediction set in 2:1 ratio, calibration set 192 , in which fertilized eggs 160 and unfertilized eggs 30; prediction set 96, in which fertilized eggs 80 and unfertilized eggs 16. Calibration set area ratio scatter and its normal probability density were shown in Figures 7 and 8, the judgment results were shown in Table 2. 


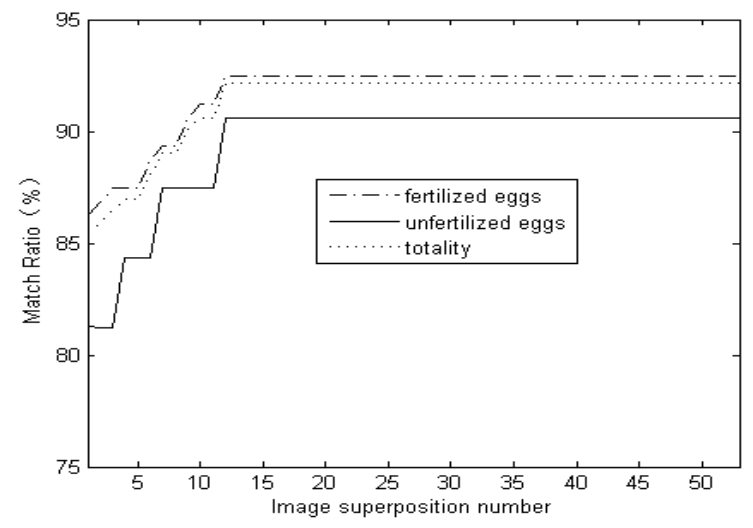

Figure 7. Judging Accuracy of Hatching Eggs Time Series Images Superimposed with Different Numbers

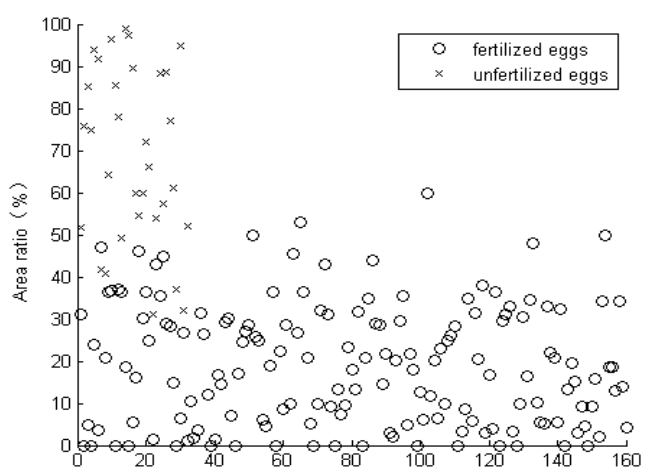

Figure 8. Scatterplot of Hatching Eggs Area Ratio in 4 Days incubation

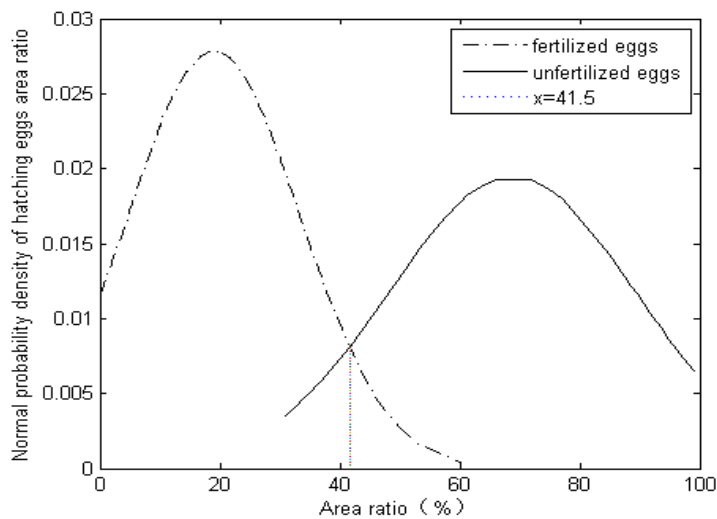

Figure 9. Normal probability density hatching eggs area ratio in 4 days Incubation 
Table 2. Model Discrimination Results of Hatching Eggs in 4 Days Incubation

\begin{tabular}{|c|c|c|c|c|c|c|}
\hline & \multicolumn{3}{|c|}{ Calibration set } & \multicolumn{3}{c|}{ Prediction set } \\
\cline { 2 - 7 } & $\begin{array}{c}\text { fertilized } \\
\text { eggs }\end{array}$ & $\begin{array}{c}\text { unfertilized } \\
\text { eggs }\end{array}$ & total & $\begin{array}{c}\text { fertilized } \\
\text { eggs }\end{array}$ & $\begin{array}{c}\text { unfertilized } \\
\text { eggs }\end{array}$ & total \\
\hline $\begin{array}{c}\text { Sample } \\
\text { numbers }\end{array}$ & 160 & 32 & 192 & 80 & 16 & 96 \\
\hline $\begin{array}{c}\text { Correct } \\
\text { numbers }\end{array}$ & 148 & 29 & 177 & 73 & 13 & 86 \\
\hline $\begin{array}{c}\text { Judging } \\
\text { accuracy/\% }\end{array}$ & 92.5 & 90.1 & 92.2 & 91.2 & 81.3 & 89.6 \\
\hline
\end{tabular}

\subsubsection{Identification of Dead Embryo Eggs}

Dead embryo eggs in incubator 16 day would be rolled into hatcher, the area ratio in incubating 16 day was seen characteristic parameter. Test parameters were determined as above, specific results shown in Figure 9. Therefore, 9 thermal images after leaving incubator 2-4min were superimposed and the activity of hatching eggs could be determined. 240 fertilized eggs were divided into calibration set and prediction set in 2:1 ratio, calibration set 160, in which fertilized eggs 154 and unfertilized eggs 6; prediction set 80 , in which fertilized eggs 76 and non-fertilized eggs 4 . Calibration set area ratio scatter and its normal probability density were shown in Figures 10 and 11, the judgment results were shown in Table 3.

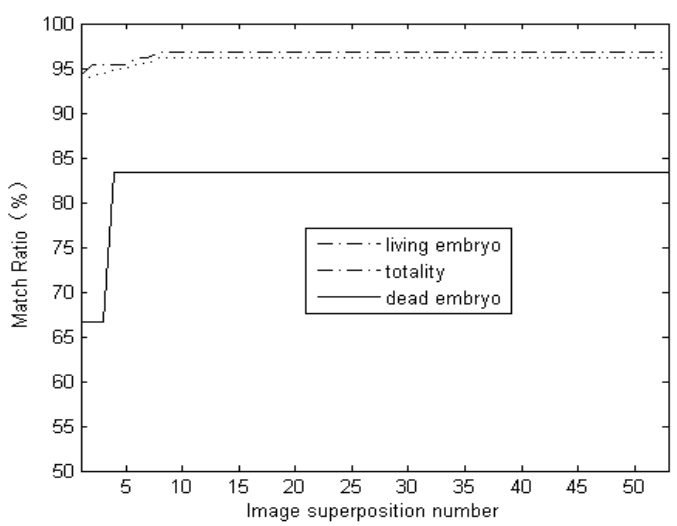

Figure 10. Judging Accuracy of Fertilized Eggs Time Series Images Superimposed with Different Numbers

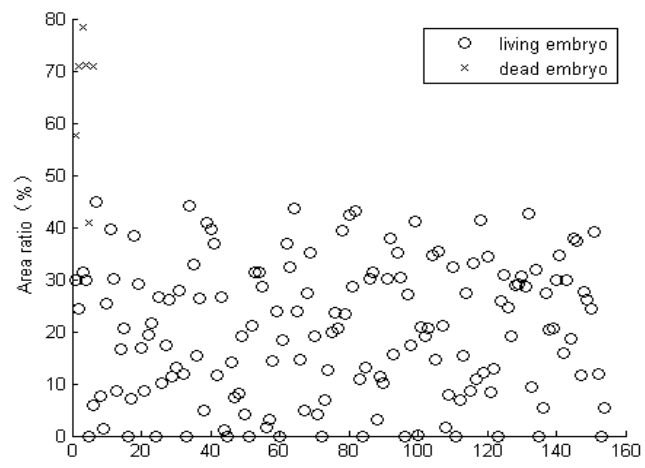

Figure 11. Scatterplot of Hatching Eggs Area Ratio in 16 Days Incubation 


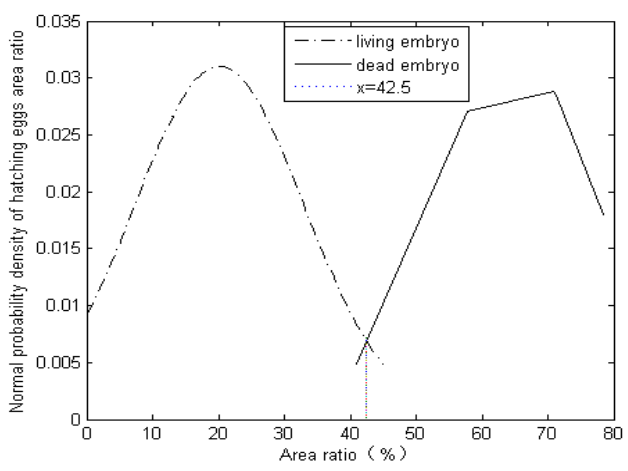

\section{Figure 12. Normal Probability Density Hatching Eggs Area Ratio in 16 Days Incubation}

\section{Table 3. Model Discrimination Results of Hatching Eggs in 16 Days} Incubation

\begin{tabular}{|c|c|c|c|c|c|c|}
\hline & \multicolumn{3}{|c|}{ Calibration set } & \multicolumn{3}{c|}{ Prediction set } \\
\cline { 2 - 7 } & $\begin{array}{c}\text { living } \\
\text { embryo }\end{array}$ & $\begin{array}{c}\text { dead } \\
\text { embryo }\end{array}$ & total & $\begin{array}{c}\text { living } \\
\text { embryo }\end{array}$ & $\begin{array}{c}\text { dead } \\
\text { embryo }\end{array}$ & total \\
\hline Sample numbers & 154 & 6 & 160 & 76 & 4 & 80 \\
\hline Correct numbers & 149 & 5 & 154 & 73 & 4 & 74 \\
\hline $\begin{array}{c}\text { Judging } \\
\text { accuracy/\% }\end{array}$ & 96.8 & 83.3 & 96.3 & 96.1 & 100 & 96.3 \\
\hline
\end{tabular}

\section{Conclusion}

Based on thermal imaging technology hatching eggs time-series images in natural cooling process were collected in hatching 4-16 day, the features of cooling curve and cooling area were analyzed. Combining with digital image technology the ROI of hatching eggs were extracted, with image enhancement the distinguishability of different active of hatching eggs were improved. The ratio of gray value $\leqq 150$ and entire ROI area was seen as characteristic parameters and the decision threshold according to minimum error rate Bayes rule was set to determine the activity of hatching eggs. The results showed by this method unfertilized eggs could be recognized in 5 min with 4 days of incubation and its overall discrimination rate was $89.6 \%$. Dead embryo eggs could be recognized in $4 \mathrm{~min}$ with 16 days of incubation and its overall discrimination rate was 96.3\%. The method could be applied to the activity of hatching eggs non-destructive testing, surface temperature distribution would be focused on researched later in order to identification of hatching eggs in a more short time.

\section{References}

[1] A. M King'ori, "Review of the factors that influence egg fertility and hatchability in poultry", International Journal of poultry science, vol. 10, no.6, (2011), pp.483-492.

[2] M. X. Y. Shujuan, "Unfertilized Eggs Verification System before Hatching Based on Embedded System and Machine Vision", Transactions of the Chinese Society for Agricultural Machinery, vol.5, (2011), pp.035.

[3] Q. H. Wang, "Non-destructive detection of hatching egg's survival based on machine vision", Journal of Food, Agriculture \& Environment, vol.10, no.1, (2012), pp.578-581.

[4] L. Liu and M. O. Ngadi, "Detecting fertility and early embryo development of chicken eggs using nearinfrared hyperspectral imaging", Food and Bioprocess Technology, vol.6, no.9, (2013), pp. 2503-2513.

[5] P. M. Coucke, "Monitoring embryo development in chicken eggs using acoustic resonance analysis", Biotechnology progress, vol.13, no.4, (1997), pp.474-478. 
[6] W. Zhang, "Comparison of spectral and image morphological analysis for egg early hatching property detection based on hyperspectral imaging", PloS one, vol.9, no.2, (2014).

[7] É. Belin, "Thermography versus chlorophyll fluorescence imaging for detection and quantification of apple scab", Computers and electronics in agriculture, vol.90, (2013), pp.159-163.

[8] D. M. Bulanon, T. F. Burks, and V. Alchanatis, "Visible and Thermal Images for Fruit Detection", Encyclopedia of Agrophysics. Springer Netherlands, (2014), pp.944-954.

[9] V. Chelladurai, D. S. Jayas, and N. D. G. White, "Thermal imaging for detecting fungal infection in stored wheat", Journal of stored products research, vol.46, no.3, (2010), pp.174-179.

[10] S. Zia, "Infrared Thermal Imaging as a Rapid Tool for Identifying Water - Stress Tolerant Maize Genotypes of Different Phenology", Journal of Agronomy and Crop Science, vol.199, no.2, (2013), pp.75-84.

[11] Y. M. Awad, "Early Detection of Powdery Mildew Disease in Wheat (Triticum aestivum L.) Using Thermal Imaging Technique", Intelligent Systems' 2014, Springer International Publishing, (2015), pp.755-765.

[12] G. Ginesu, "Detection of foreign bodies in food by thermal image processing", Industrial Electronics, IEEE Transactions on, vol.51, no.2, (2004), pp.480-490.

[13] L. Senni, "On-line automatic detection of foreign bodies in biscuits by infrared thermography and image processing", Journal of Food Engineering, vol.128, (2014), pp.146-156.

[14] A. Danno, M. Miyazato, and E. Ishiguro, "Quality Evaluation of Agricultural Products by Infrared Imaging Method: II. Discrimination of Fertilized and Unfertilized Eggs during the Incubation Period", Memoirs of the Faculty of Agriculture, Kagoshima University, vol.15, (1979), pp.145-158.

[15] C.-S. Lin, "The identification and filtering of fertilized eggs with a thermal imaging system", Computers and electronics in agriculture, vol.91, (2013), pp.94-105. 
International Journal of Smart Home

Vol. 10, No. 2, (2016) 